\title{
Dependence of electrical properties of composition material from the structure of the matrix
}

\author{
K.V. Kirilenko \\ Frantsevich Institute for Problems of Materials Science of NASU, 3, Krzhyzhanovsky St., Kyiv, 03142, Ukraine \\ Tel.: +380444241531 \\ E-mail:vvk@ipms.kiev.ua
}

Article info: received 05.09.2019, revised 13.09.2019, accepted 27.09.2019

Kirilenko, K.V. (2019) Dependence of electrical properties of composition material from the structure of the matrix, 3(44), doi: 10.26909/csl.3.2019.3

In the context of rising energy costs and the need to use new energy sources, works aimed at raising the surface temperature of heat radiators with reduced energy consumption are of particular importance, and it is especially important if these processes are also accompanied by the effects of self-stabilization. Bulk materials do not possess these properties. However, materials whose dielectric matrix is also an active element can provide up to $10-30 \%$ of the thermal energy that will be released in the material, thereby increasing the surface temperature and without increasing energy consumption. Therefore, the study of composite materials with different matrices is relevant.

This article the influence of the matrix material on the electrical properties of composite materials was examined. It was established that the microstructure morphology of resistive materials changes significantly depending on the matrix type. In composites based on matrix AlN, for the entire range of concentrations $\mathrm{HfC}$, conducting cluster is formed with a metallic conductivity. For composite systems $\mathrm{Al}_{2} \mathrm{O}_{3}-\mathrm{HfC}$ and $\mathrm{Si}_{3} \mathrm{~N}_{4}-\mathrm{HfC}$ thermoactivated hopping conduction between nearest neighboring states observed. Thus, for materials based on $\mathrm{Si}_{3} \mathrm{~N}_{4}$ matrix at temperatures up to $300{ }^{\circ} \mathrm{C}$ observed reduction of charge carriers concentration with increasing temperature.

The approximation of the temperature dependence of the electrical conductivity was carried out on the basis of the following possible variants of the nature of the electrical conductivity, namely: jump conductivity (nonlocalized states, localized states in the tails of conduction and valence bands, localized states near the Fermi level), tunneling.

It can be assumed that the formation of conductive clusters occurred under the influence of two factors: magnetic field and mechanical loading. When using the AIN matrix, the influence of the magnetic field on the structure formation is smallest. This conclusion can be drawn from the fact that the formed conductive clusters have the appearance of a linear chain structure.

Key words: AlN matrix, matrix material, composition, metallic conductivity composite systems.

\section{Залежність електричних властивостей композиційного матеріалу від структури матриці}

\author{
К.В. Кириленко
}

Інститут проблем матеріалознавства НАН України, Київ, Україна

У статті розглянуто вплив матеріалу матриці на електричні властивості композиційних матеріалів. Встановлено, що в залежності від типу матриці суттєво змінюється морфологія мікроструктури матеріалів резистивного шару. В композитах на основі матриці AlN, для всього діапазону концентрацій НfC, формується провідний кластер 3 металічним типом провідності. Для композитів систем $\mathrm{Al}_{2} \mathrm{O}_{3}-\mathrm{HfC}$ i $\mathrm{Si}_{3} \mathrm{~N}_{4}$-HfC спостерігається термоактивована стрибкова провідність між найближчими сусідніми станами. Причому для матеріалів на основі матриці $\mathrm{Si}_{3} \mathrm{~N}_{4}$ при температурах до $300{ }^{\circ} \mathrm{C}$ додатково спостерігається зниження концентрації носіїв заряду з ростом температури. 


\section{Умовні позначення та скорочення}

ГП - гаряче пресування; МДН - метал-діелектрик-напівпровідник; $T_{\text {вит }}$ - температура ізотермічної витримки, ${ }^{\circ} \mathrm{C} ; t_{\text {вит }}-$ час ізотермічної витримки, хв.; $P_{\text {вит }}$ - тиск витримки, МПа; $\mathrm{V}_{\text {нагр }}-$ швидкість нагріву, $\%$ хв.; $V$ охол - швидкість охолодження, ${ }^{\circ}$ хв.; $\rho$ - питомий опір, Ом·см; $T$ - температура, ${ }^{\circ} \mathrm{C} ; x_{\mathrm{c}}-$ порогова концентрація, об. долей; $t$ - коефіцієнт, що характеризує форму частинок провідної фази.

\section{ВстуII}

Мікромініатюризація електротехнічних пристроїв призводить до розвитку нового напрямку композиційних нагрівальних систем на основі напівпровідникових матеріалів (OMEGA Engineering, INC., USA [1]), керамічних матеріалів з матрицями $\mathrm{Al}_{2} \mathrm{O}_{3}, \mathrm{Si}_{3} \mathrm{~N}_{4}, \mathrm{AlN}$ (KYOCERA Corporation, Japan [2], IПМ НАНУ, Україна [3]).

Для формування активного резистивного шару в таких нагрівальних елементах використовуються різні добавки: $\mathrm{TiN}[4,5], \mathrm{MoSi}_{2}[6,7], \mathrm{TaN}$ [8], $\mathrm{SiC}$ [9], $\mathrm{Y}_{2} \mathrm{O}_{3}$ [10]. Перспективною провідною добавкою, що працює в області високих температур, $є$ HfC [11]. Тому важливо для цієї сполуки підібрати діелектричну матрицю, в якій буде реалізований комплекс оптимальних параметрів резистивного шару, таких, як значення питомого опору та його відтворюваність, величина і знак температурного коефіцієнта опору.

В умовах подорожчання енергоресурсів і необхідності використовувати нові джерела енергії практичну значимість мають роботи направлені на підвищення температури поверхні тепловипромінювачів при зниженому енергоспоживанні, і особливо важливо, якщо ці процеси також супроводжуються ефектами самостабілізації. Об'ємні матеріали цими властивостями не володіють. Однак матеріали, діелектрична матриця яких також є активним елементом, можуть дати додатково до 10 - 30 \% теплової енергії, яка буде виділятися в матеріалі, тим самим підвищуючи температуру поверхні і не збільшуючи енергоспоживання. Отже, актуальним є дослідження композитних матеріалів 3 різними матрицями. Перспективними матеріалами для високотемпературної діелектричної матриці можуть бути $\mathrm{Al}_{2} \mathrm{O}_{3}$ $[5,7], \mathrm{Si}_{3} \mathrm{~N}_{4}[4,6,8,9]$, AlN [10].

\section{Мета роботи}

Метою нашої роботи є вивчення властивостей нагрівальних елементів виготовлених на основі трьох видів матриць ( $\left.\mathrm{AlN}, \mathrm{Al}_{2} \mathrm{O}_{3}, \mathrm{Si}_{3} \mathrm{~N}_{4}\right)$ та провідної добавки НfC.

\section{Матеріали та методи дослідження}

Зразки нагрівальних елементів виготовлялися методом шарувато-градієнтної технології [12].

Для вивчення впливу матриці в якості діелектрика, як діелектричного шару так і діелектричної основи провідного шару, використовувались три типи найбільш поширених високотемпературних діелектриків: а) $\mathrm{AlN}^{1}$ активований $\mathrm{TiO}_{2}{ }^{1}$ в кількості 2 об. \%; б) $\mathrm{Al}_{2} \mathrm{O}_{3}{ }^{2}$ активований композицією $\mathrm{SiO}_{2}{ }^{3}: \mathrm{CaO}^{3}: \mathrm{MgO}^{3}=16,5: 1: 6$ в кількості 4,7 об. $\%$; в) $\mathrm{Si}_{3} \mathrm{~N}_{4}^{4}$ активований $\mathrm{Al}_{2} \mathrm{O}_{3}$ в кількості 7 об. \%. В якості провідної добавки використовувались порошки $\mathrm{HfC}^{1}$ в кількості від 11 до 17 об. \%. ( ${ }^{1}$ - виробництво Донецького заводу хімічних реактивів; ${ }^{2}$ - Миколаївський глиноземний завод; ${ }^{3}-$ випущено у відповідності до діючих стандартів з чистотою ЧДА; ${ }^{4}$ - Бакинський завод порошкової металургії, Азербайджан).

Підготовлені заготовки спікались в індукційній печі методом ГП. Параметри процесу ГП наведені в таблиці 1.

Розмір отриманих зразків 50х8х6 мм. Після шліфування на активні області для забезпечення кращого контакту наносилась срібна паста.

Вимірювання питомого опору зразків проводилось методом вольтметра - амперметра. Нагрівання зразків забезпечувалось подачею постійного електричного струму від джерела живлення GW GPR-11H300 (припустима похибка

Таблиця 1.

Параметри процесу

\begin{tabular}{|c|c|c|c|c|c|}
\hline Зразок & $V_{\text {нагр }}$, $/$ хв. & $T_{\text {вит }},{ }^{\circ} \mathrm{C}$ & $t_{\text {вит }}$, хв. & $P_{\text {вит }}$, МПа & $V_{\text {охол }}$, хв. \\
\hline $\mathrm{AlN}-\mathrm{HfC}$ & 40 & 1970 & 25 & 3800 & 20 \\
\hline $\mathrm{Al}_{2} \mathrm{O}_{3}$-HfC & 40 & 1550 & 15 & 3800 & 30 \\
\hline $\mathrm{Si}_{3} \mathrm{~N}_{4}$-HfC & 40 & 1820 & 20 & 3800 & 30 \\
\hline
\end{tabular}


$\leq \pm\left(0,005 \cdot U_{y c m}+100 \mathrm{мB}\right)$ при режимі стабілізації напруги, або $\leq \pm\left(0,005 \cdot I_{y c m}+1 м A\right)$ при режимі стабілізації струму). Для визначення напруги використовувався цифровий мультиметр АРРА - 207 (припустима похибка $\leq \pm\left(0,0006 \cdot U_{u з м}+8 d\right)$ ), для вимірювання струму використовувався цифровий мультиметр FLUKE - 189 (припустима похибка $\leq \pm\left(0,0025 \cdot I_{\text {изм }}+0,2\right.$ мкА $\left.)\right)$. Для вимірювання температури, до якої зразок нагрівся під дією електричного струму, використовувався оптичний пірометр Raytek MX4 TD (похибка вимірювання $\left.\pm 0,0075 \cdot T_{\text {изм }}\right)$.

Для апроксимації концентраційної залежності електропровідності використовувалось рівняння узагальненої теорії ефективного середовища (рівняння McLachlan'a [13]). Для заданих параметрів $\sigma_{c}, \sigma_{\mathrm{i}}, \varphi_{\mathrm{c}}, \mathrm{s}$ i t рахувалось значення $\sigma_{\mathrm{m}}$ в кожній точці $\mathrm{f}_{\mathrm{c}}$, що змінювалось 3 кроком 0,01 .

Фотографії мікроструктури досліджуваних матеріалів аналізувались за допомогою комплексу SIAMS. Була розрахована об'ємна доля, середня хорда провідних включень та середня відстань між ними.

\section{Результати та їх обговорення}

Пористість композитів системи AlN-HfC становила від 0,5\% до 2,5\%, $\mathrm{Al}_{2} \mathrm{O}_{3}$ - $\mathrm{HfC}$ - від 1,5\% до $6 \%, \mathrm{Si}_{3} \mathrm{~N}_{4}-\mathrm{HfC}$ - від 0,5\% до $3 \%$. Нами була досліджена мікроструктура виготовлених зразків (рис. 1), а також температурні залежності питомого опору композитів при різних концентраціях провідної добавки HfC (рис. 2, 3).
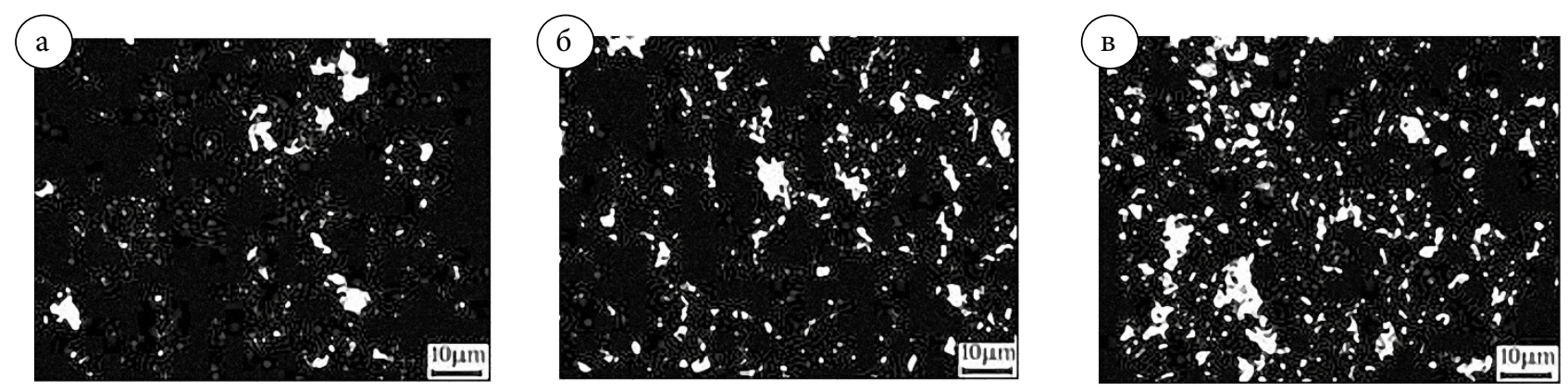

Рис. 1. Мікроструктура перерізу резистивного шару сформована за участю різних матеріалів матриць: a) $\mathrm{Al}_{2} \mathrm{O}_{3}$; б) $\mathrm{AlN}$; в) $\mathrm{Si}_{3} \mathrm{~N}_{4}$. Введена концентрація провідної добавки $\mathrm{HfC}-11$ об. \%

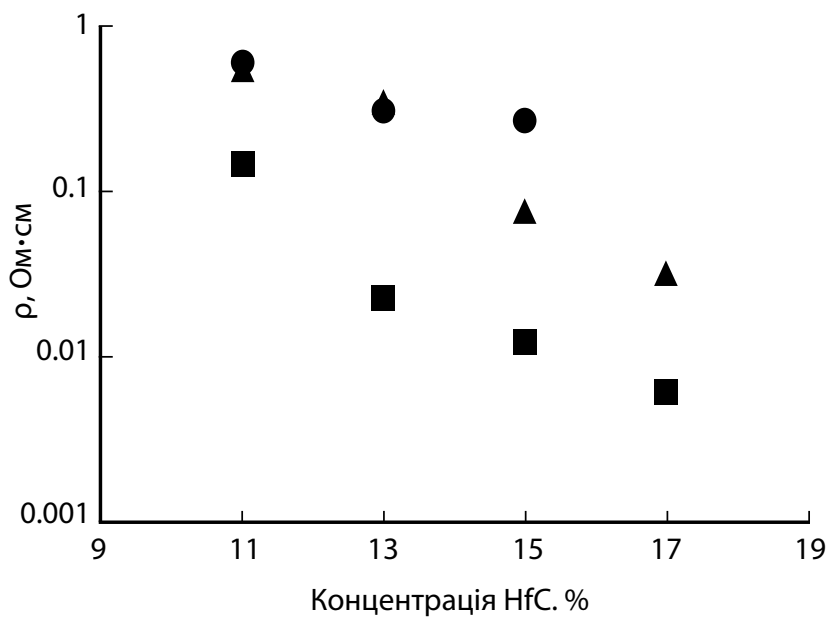

Рис. 2. Концентраційна залежність питомого опору резистивних композиційних матеріалів з різними матеріалами діелектричної матриці:

$$
\text { - }-\mathrm{Al}_{2} \mathrm{O}_{3}, \boldsymbol{\Delta}-\mathrm{Si}_{3} \mathrm{~N}_{4}, \boldsymbol{\square}-\mathrm{AlN}
$$

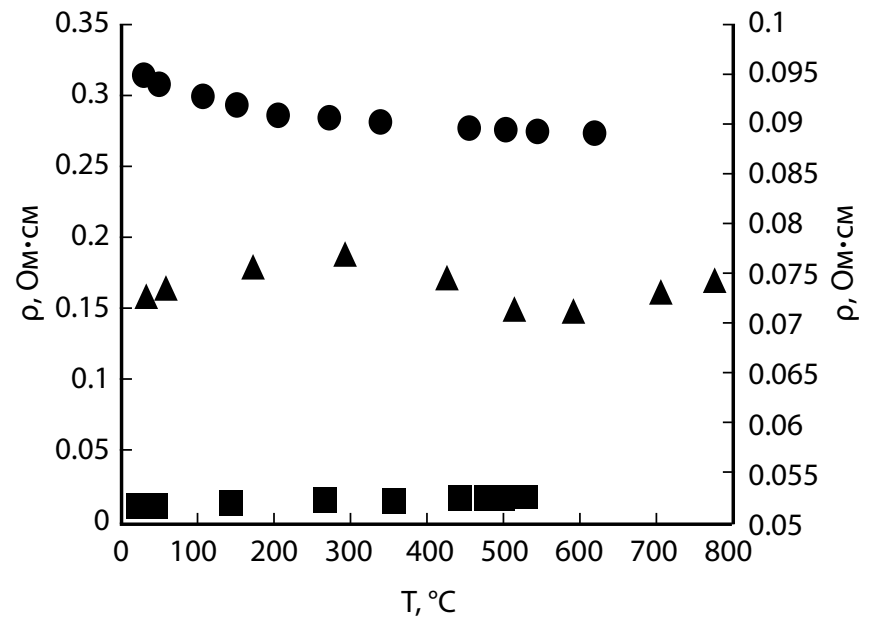

Рис. 3. Залежність питомого опору від температури резистивних композиційних матеріалів з різними матеріалами діелектричної матриці:

- - $\mathrm{Al}_{2} \mathrm{O}_{3}$ (шкала зліва), ш - $\mathrm{AlN}$ (шкала зліва), $\boldsymbol{\Delta}-\mathrm{Si}_{3} \mathrm{~N}_{4}$ (шкала справа).

Концентрація провідної добавки HfC - 15 об. \% 
Як показано на рис. 1, морфологія мікроструктури матеріалів резистивного шару з використанням різних матеріалів суттєво відрізняється. Провідна фаза в перерізі в напрямку гарячого пресування відрізняється як концентрацією, так і розміром частинок, а також формою чи морфологією провідних кластерів. Характеристики частинок провідної фази приведені в таблиці 2.

Присутність на зображенні частинок значної величини говорить про ступінь агрегації провідної фази, яка відбувалася найбільш вірогідно в процесі на етапі змішування, тому що в технічних процесах гарячого пресування неможливий такий інтенсивний масоперенос. В результаті аналізу декількох зображень, зроблених на різних ділянках поверхні зразку, встановлено, що найбільша агрегація НfC відбувалася при використанні матриці $\mathrm{Al}_{2} \mathrm{O}_{3}$. $\mathrm{B} \mathrm{Al}_{2} \mathrm{O}_{3}$ агрегати НfC мали форму близьку до ізометричної $\mathrm{i}$ максимальний розмір агрегатів був 20 мкм. Агрегати $\mathrm{HfC}$ у $\mathrm{AlN}$ та $\mathrm{Si}_{3} \mathrm{~N}_{4}$ являли собою видовжені частинки розмірами 3 - 5 мкм.

Виходячи 3 того, що середня концентрація фази включень в композиції з матеріалу $\mathrm{Al}_{2} \mathrm{O}_{3}$ в 2 рази менша, ніж введена, а розмір частинок HfC переважно відповідає розміру частинок вихідного порошку (1 - 1,5 мкм), можна зробити висновок, що в $\mathrm{Al}_{2} \mathrm{O}_{3}$ частинки включень HfC мають вигляд видовжених циліндрів, орієнтованих в напрямку, перпендикулярному напрямку гарячого пресування.

Можна припустити, що формування провідних кластерів відбувалося під дією двох чинників: магнітного поля і механічного навантаження. При використанні матриці AlN вплив магнітного поля на формування структури є найменшим. Цей висновок можна зробити виходячи 3 того, що утворені провідні кластери мають вигляд лінійної ланцюгової структури.

Найбільш однорідне розподілення частинок фази включення спостерігається при використанні матриці $\mathrm{Si}_{3} \mathrm{~N}_{4}$, проте в оточенні основного провід- ного кластеру явно видно присутність угрупувань кільцевої форми. Виходячи з того, що об'ємна доля частинок в напрямку гарячого пресування на 4 \% більше тієї долі включень, що було введено в суміш на етапі змішування, можна припустити, що формування кластерів в матеріалі $\mathrm{Si}_{3} \mathrm{~N}_{4}$ відбувалось за рахунок утворення видовжених агрегатів, орієнтованих у напрямку гарячого пресування. Відповідно i середня хорда частинок $3 \mathrm{Si}_{3} \mathrm{~N}_{4} \epsilon$ максимальною, а середня відстань між частинками - мінімальною.

Концентраційна залежність питомого опору резистивних композиційних матеріалів представлена на рис. 2.

Як видно 3 рис. 2, питомий опір резистивного шару всіх композиційних матеріалів зменшується зі збільшенням концентрації провідної добавки HfC. При найнижчих 3 досліджуваних концентрацій HfC (11 об. \%) в складі резистивного шару питомий опір знаходиться в діапазоні 0,1 - 1 Ом·см. Така мала величина питомого опору, згідно з теорією перколяції, свідчить про те, що всі концентрації добавки в отриманих композитах відповідають області за порогом перколяції. Для матеріалів системи $\mathrm{Al}_{2} \mathrm{O}_{3}$-HfC i Si $\mathrm{N}_{4}$-HfC спочатку значення питомого опору співпадають при концентрації HfC 11 - 13 об. \%. Проте при більших концентраціях добавки опір резистивного шару композитів $\mathrm{Si}_{3} \mathrm{~N}_{4}$-HfC стає значно меншим ніж опір композиту $\mathrm{Al}_{2} \mathrm{O}_{3}$ - $\mathrm{HfC} 3$ тією ж концентрацією. Найнижчий опір у всьому діапазоні досліджуваних концентрацій мають композити на основі AlN.

Залежність питомого опору від температури досліджуваних матеріалів представлено на рис. 3 .

Як видно з рис. 3, залежність питомого опору від температури для матеріалів з матрицею AlN носить лінійний характер, причому значення питомого опору збільшується зі збільшенням температури (від 0,012 Ом · см при $20^{\circ} \mathrm{C}$ до 0,017 Ом·см при $530{ }^{\circ} \mathrm{C}$ ).

В композитах 3 матрицею на основі $\mathrm{Si}_{3} \mathrm{~N}_{4}$ залежність питомого опору від температури носить не-

Таблиця 2.

Характеристики частинок провідної добавки для мікроструктур, наведених на рис. 1

\begin{tabular}{|c|c|c|c|}
\hline \multirow{2}{*}{ Параметр } & \multicolumn{3}{|c|}{ Матеріал матриці } \\
\cline { 2 - 4 } & $A l N$ & $\mathrm{Si}_{3} \mathrm{~N}_{4}$ & $\mathrm{Al}_{2} \mathrm{O}_{3}$ \\
\hline Об'ємна доля & 0,079 & 0,146 & 0,053 \\
\hline Середня хорда, мкм & 1,652 & 1,816 & 1,579 \\
\hline Середня відстань між частинками, мкм & 20,223 & 11,331 & 33,454 \\
\hline
\end{tabular}


лінійний характер. Спочатку питомий опір зростає на $5 \%$ і набуває свого максимуму при температурі $300{ }^{\circ} \mathrm{C}$, потім спадає на $2 \%$ до температури $600{ }^{\circ} \mathrm{C}$ i далі знову починає зростати .

$\mathrm{B}$ композитах 3 матрицею на основі $\mathrm{Al}_{2} \mathrm{O}_{3}$ питомий опір безперервно зменшується зі збільшенням температури (від 0,31 Ом·см при $30{ }^{\circ} \mathrm{C}$ до 0,27 Ом·см при $\left.620^{\circ} \mathrm{C}\right)$.

При зміні концентрації провідної добавки НfC (11 - 17 \%) характер залежності питомого опору від температури, незалежно від матеріалу діелектричної матриці, не змінюється, відповідні криві лише зсуваються по шкалі питомого опору.

Використовуючи загальне рівняння ефективного середовища [13], були змодельовані залежності питомого опору від концентрації провідної добавки. Оскільки ми працюємо з даними питомого опору, котрі знаходяться в післяпороговій області, то підбирались лише коефіцієнти $\mathrm{t}$ та $\mathrm{x}$, так як саме вони відповідають за характер даних кривих у відповідній залежності. Результат моделювання представлений на рис. 4.

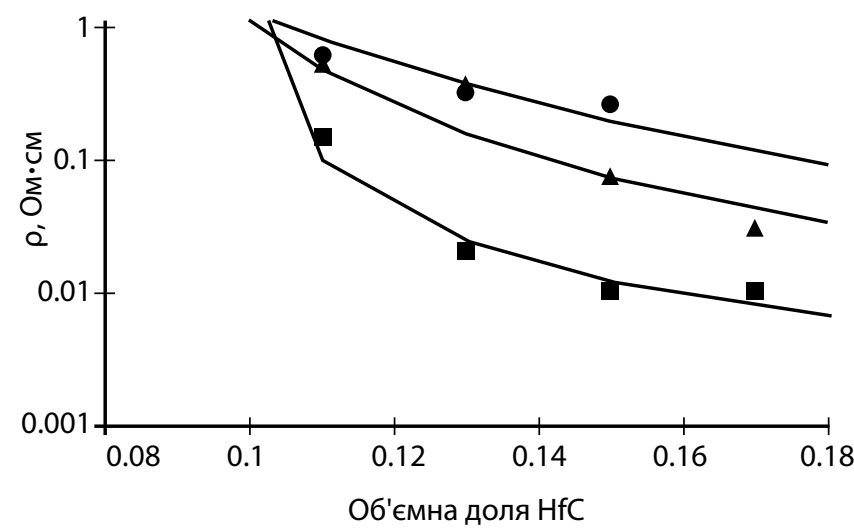

Рис. 4. Результат моделювання концентраційної залежності питомого опору зразків з табл. 1:

$$
\text { - }-\mathrm{Al}_{2} \mathrm{O}_{3}, \mathbf{\Delta}-\mathrm{Si}_{3} \mathrm{~N}_{4}, \mathbf{-}-\mathrm{AlN}
$$

Параметри, отримані в результаті моделювання, представлені в таблиці 3.

Поріг перколяції має найбільше значення для системи AlN-HfC.

Результати моделювання показують, що в матрицях на основі $\mathrm{Al}_{2} \mathrm{O}_{3}$ i $\mathrm{AlN}$ кластери формуються у вигляді двомірних утворень, видовжених у напрямку перпендикулярному до напрямку гарячого пресування. Індекс $t$, рівний 2,2 для матеріалів системи $\mathrm{Si}_{3} \mathrm{~N}_{4}$-HfC, відповідає тому фактору, що спостерігається при аналізі мікроструктури, тобто агрегати являють собою циліндри, що видовжені у напрямку гарячого пресування.

Апроксимація температурної залежності електропровідності проводилась виходячи з наступних можливих варіантів природи електропровідності, a саме: стрибкова провідність (по нелокалізованим станам, по локалізованим станам в хвостах зон провідності і валентної зони, по локалізованим станам біля рівня Фермі), тунелювання, багатофононний процес переносу заряду.

Для композитів системи AlN-HfC, для всього досліджуваного діапазону концентрацій добавки HfC характерна лінійна залежність питомого опору від температури в координатах $\rho(\mathrm{T})$, що говорить про металічний характер провідності таких матеріалів. (рис. 5, а).

Для композитів 3 матрицею на основі $\mathrm{Al}_{2} \mathrm{O}_{3}$ (рис. 5, б) спостерігається термоактивована стрибкова провідність між найближчими сусідніми станами, причому енергія активації стрибка, що відповідає ширині зони локалізованих станів, становить $5,3 \cdot 10^{-3}$ eВ. В композитах 3 матрицею на основі $\mathrm{Si}_{3} \mathrm{~N}_{4}$ в діапазоні температур $0-300{ }^{\circ} \mathrm{C}$ спостерігається механізм термостимульованого зменшення концентрації носіїв на пастках, подібно як це відбувається в МДН структурах з плаваючим чи ізольованим затвором. 3 подальшим збільшенням температури від $300{ }^{\circ} \mathrm{C}$ до $500{ }^{\circ} \mathrm{C}$ механізм переносу зарядів подібний до матеріалів системи $\mathrm{Al}_{2} \mathrm{O}_{3}-\mathrm{HfC}$, проте

Таблиця 3.

Результати моделювання (параметри)

\begin{tabular}{|c|c|c|}
\hline & & \\
Матеріал & $t$ & $x_{c}$ \\
\hline $\mathrm{AlN}-\mathrm{HfC}$ & 1,35 & 0,099 \\
\hline $\mathrm{Si}_{3} \mathrm{~N}_{4}-\mathrm{HfC}$ & 2,2 & 0,08 \\
\hline $\mathrm{Al}_{2} \mathrm{O}_{3}-\mathrm{HfC}$ & 1,1 & 0,08 \\
\hline
\end{tabular}


енергія активації стрибка складає від $1,84 \cdot 10^{-2}$ еВ до $1,19 \cdot 10^{-2}$ еВ при збільшенні концентрації добавки НfС від 11 до $17 \%$ (рис. 5, в).

Враховуючи наведені вище вимоги до електрофізичних характеристик нагрівального елемента на основі керамічних композицій і виходячи з отриманих результатів, можна рекомендувати для виготовлення резистивних шарів керамічних нагрівачів композицію AlN-HfC, яка має необхідний рівень питомого опору та позитивної ТКО в усьому діапазоні робочих температур, або $\mathrm{Si}_{3} \mathrm{~N}_{4}-\mathrm{HfC}$, в якій відбувається самостабілізація електропровідності і загальний температурний коефіцієнт опору нагрівального елемента в широкому інтервалі температур близький до нуля.

\section{Висновки}

1. Встановлено, що в залежності від типу матриці суттєво змінюється морфологія мікроструктури матеріалів резистивного шару. Найбільша агрегація HfC відбувається при використанні матриці $\mathrm{Al}_{2} \mathrm{O}_{3}$. Частинки фази включення в матеріалах на основі матриці $\mathrm{Si}_{3} \mathrm{~N}_{4}$ мають форму видовжених циліндрів або агрегатів, що направлені в напрямку гарячого пресування. При використанні матриці $\mathrm{Al}_{2} \mathrm{O}_{3}$ відповідні частинки направлені в напрямку перпендикулярному напрямку гарячого пресування. При використанні матриці AIN утворені провідні кластери мають вигляд лінійної ланцюгової структури.

2. Встановлено, що в композитах на основі матриці AlN, для всього діапазону концентрацій HfC, формується провідний кластер з металічним типом провідності. Відповідні матеріали мають позитивний ТКО (від 0,00085 1/K при $40{ }^{\circ} \mathrm{C}$ до 0,00065 1/K при $300{ }^{\circ} \mathrm{C}$ ) в усьому діапазоні досліджуваних температур.

3. Композити систем $\mathrm{Al}_{2} \mathrm{O}_{3}-\mathrm{HfC}$ i $\mathrm{Si}_{3} \mathrm{~N}_{4}$-HfC характеризуються більш складною залежністю питомого опору від температури, яка крім того ще й залежить від концентрації добавки НfC. У відповідних композитах спостерігається термоактивована стрибкова провідність між найближчими сусідніми станами. Причому для матеріалів на основі матриці $\mathrm{Si}_{3} \mathrm{~N}_{4}$ при температурах до $300{ }^{\circ} \mathrm{C}$ додатково спостерігається явище виснаження концентрації носіїв заряду з ростом температури, яке може виникати, якщо створюються системи типу МДН структур 3 плаваючим чи ізольованим затвором.

4. Найбільш придатною для виготовлення керамічних резистивних шарів для електричних нагрівачів є композиція AlN-HfC, яка має необхідний рівень питомого опору та позитивної ТКО в усьому діапазоні робочих температур та $\mathrm{Si}_{3} \mathrm{~N}_{4}-\mathrm{HfC}$, в якій відбувається самостабілізація електропровідності і

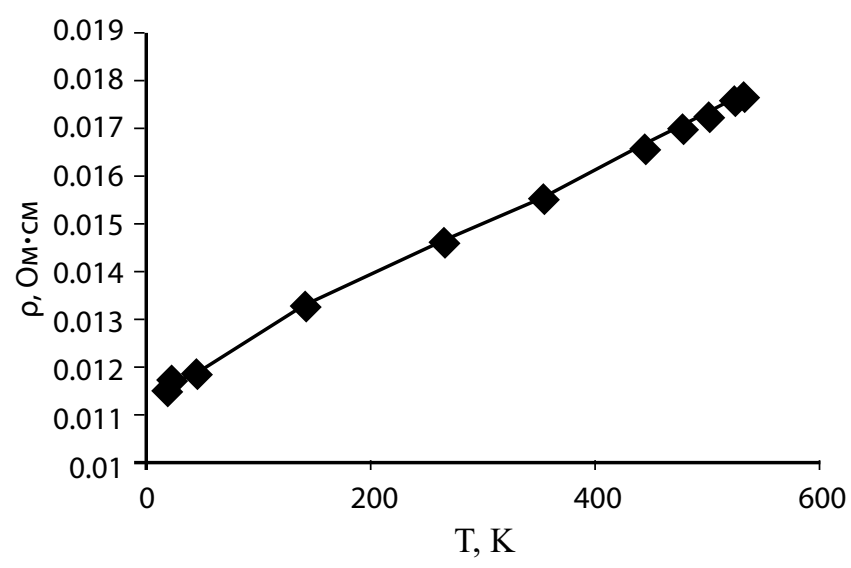

(a)



(6)

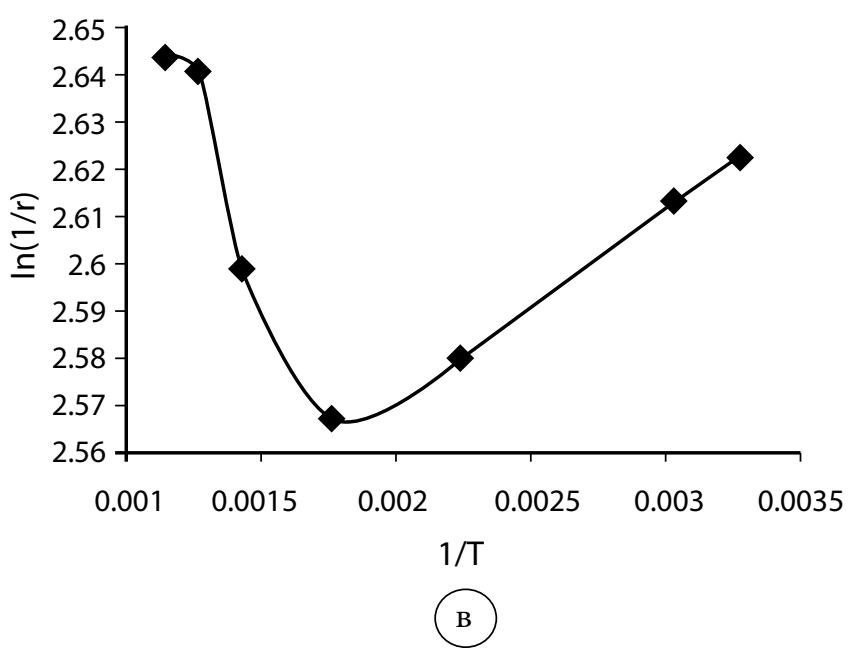

Рис. 5. Залежність питомого опору від температури резистивних композиційних матеріалів з різними матеріалами діелектричної матриці: $\mathrm{a}-\mathrm{AlN}, \sigma-\mathrm{Al}_{2} \mathrm{O}_{3}$, в $-\mathrm{Si}_{3} \mathrm{~N}_{4}$. Концентрація провідної добавки $\mathrm{HfC}$ - 15 об. \% 
загальний температурний коефіцієнт опору нагрівального елемента в широкому інтервалі температур близький до нуля.

\section{References}

1. www.omega.com.

2. www.global.kyocera.com.

3. Petrovsky, $V$. Electrical response on microstructure evolution of multicomponent ceramic matrix materials // Journal of Materials Scince and Engineering. - 2010. - Volume 4, №2 (Serial №27). - P. 39 - 51.

4. Norhayati Ahmad Hidekazu Sueyoshi. Properties of Si3N4-TiN composites fabricated by spark plasma sintering by using a mixture of $\mathrm{Si}_{3} \mathrm{~N}_{4}$ and Ti powders // Ceramics International 36. - 2010. - P. 491 - 496.

5. Jingguo Li, Lian Gao, Jingkun Guo. Mechanical properties and electrical conductivity of $\mathrm{TiN}-\mathrm{Al}_{2} \mathrm{O}_{3}$ nanocomposites // Journal of the European Ceramic Society 23. - 2003. - P. $69-74$.

6. Kh.V. Manukyan, S.L. Kharatyan, G. Blugan, P. Kocher, J. Kuebler. $\mathrm{MoSi}_{2}-\mathrm{Si}_{3} \mathrm{~N}_{4}$ composites: Influence of starting materials and fabrication route on electrical and mechanical properties // Journal of the European Ceramic Society 29. - 2009. - P. 2053 - 2060.

7. Stefan Köbel, Juliane Plüschke, Ulrich Vogt, Thomas J. Graule. $\mathrm{MoSi}_{2}-\mathrm{Al}_{2} \mathrm{O}_{3}$ electroconductive ceramic composites // Ceramics International 30. - 2004. P. $2105-2110$.
8. Vitaly Ya. Petrovsky, Zbigniew, S. Rak. Densication, microstructure and properties of electroconductive Si3N4 \pm TaN composites. Part II: Electrical and mechanical properties // Journal of the European Ceramic Society 21. - 2001. - P. 237 - 244.

9. Luo fa, Zhu dongmei, Su xiaolei, Zhou wancheng. Properties of hot-pressed of $\mathrm{SiC} / \mathrm{Si}_{3} \mathrm{~N}_{4}$ nanocomposites // Materials Science and Engineering A 458. - 2007. P.7 - 10 .

10. Ying-Da Yu, Aase Marie Hundere, Ragnvald Huier, Rafal E. Dunin-Borkowski, Mari-Ann Einarsrud. Microstructural characterization and microstructural effects on the thermal conductivity of $\operatorname{AlN}\left(\mathrm{Y}_{2} \mathrm{O}_{3}\right)$ ceramics // Journal of the European Ceramic Society 22. - 2002. - P. 247 - 252.

11. Raffaele Savino, Mario De Stefano Fumo, Laura Silvestroni, Diletta Sciti. Arc-jet testing on HfB2 and HfC-based ultra-high temperature ceramic materials // Journal of the European Ceramic Society 28. - 2008. P. 1899 - 1907.

12. Петровский, В.Я. Физические принципы и технологические аспекты получения градиентных композитов на основе бескислородной керамики // Порошковая металлургия. - 1998. - № 7/8. C. 50 - 54.

13. McLachlan, D.S., Blaszkiewicz, M., Newnham, R.E. Electrical Resistivity of Composes // J. Am. Ceram. Soc. - 1990. - 73 N 8. - P. 237 - 244. 